\title{
CLINICAL EXPERIENCE IN RADICAL LYMPHADENECTOMY FOR ADENOCARCINOMA OF THE GASTRIC CARDIA
}

Chung-Ping Hsu, MD

Cheng-Chung Wu, $\mathrm{MD}^{\mathrm{b}}$

Chih-Yi Chen, MD ${ }^{a}$

Nan-Yung Hsu, MD ${ }^{a}$

Jiun-Yi-Hsia, MD

Pei-Yen Wang, $\mathrm{MD}^{\mathrm{a}}$

\begin{abstract}
Objectives: We evaluated the pattern of nodal metastasis and its prognosis after radical lymphadenectomy in adenocarcinoma of the gastric cardia. Methods: We conducted a retrospective cohort study of 70 patients $(52$ men and 18 women; mean age 63.6 years) with adenocarcinomas of the gastric cardia who underwent extended gastrectomy ( 65 total gastrectomies and 5 proximal gastrectomies) and radical lymphadenectomy (D2 to D4) at Taichung Veterans General Hospital between 1989 and 1995. Results: Twenty-four complications developed in $22(31.4 \%)$ patients, and seven $(\mathbf{1 0 . 0 \%})$ hospital deaths occurred. An overall 5-year cumulative survival of $37.6 \%$ was obtained. Lymph node metastases were identified in 53 (75.7\%) patients. Nodal involvement was closely related to the depth of tumor invasion $(p=0.005)$. When the gastric wall invasion was limited to the subserosal layer ( $\mathrm{T} 1$ and $\mathrm{T} 2, n=15$ ), no patient had $\mathrm{N} 4$ group nodal metastasis. Once the serosal layer had been involved (beyond T3), N4 group nodal metastasis was frequently seen $(30.9 \%, 17$ of 55 patients). A multivariable analysis revealed that the level of nodal involvement, the depth of tumor invasion, and the presence of complications were independent prognostic factors. Cumulative 5-year survivals of curability $\mathbf{A}(n=12)$, B $(n=19)$, and $\mathrm{C}(n=32)$ resections were $100 \%, 21.2 \%$, and $27.5 \%$, respectively $(p=0.0001)$. The long-term survival of the patients after resection was also closely related to their pTNM stages $(p=0.0004)$. Conclusions: We conclude that gastrectomy accompanied by radical lymphadenectomy provides a reasonable long-term survival expectancy that is closely related to the stage of the disease and the curability of resection. (J Thorac Cardiovasc Surg 1997;114:544-51)
\end{abstract}

Surgical resection is the treatment of choice for $S$ cancer of the stomach if no distant metastases exist. Japanese experience further confirms the importance of radical lymph node dissection in addition to gastrectomy. ${ }^{1,2}$ Cancer of the gastric cardia accounts for $5 \%$ to $25 \%$ of gastric cancers. ${ }^{2-4}$ Its prevalence has been steadily increasing in Western countries in recent years. ${ }^{5}$ Different

From the Divisions of Thoracic ${ }^{\mathrm{a}}$ and General Surgery, ${ }^{\mathrm{b}}$ Department of Surgery, Taichung Veterans General Hospital, Taichung, Taiwan, Republic of China.

Received for publication July 9, 1996; revisions requested Nov. 18, 1996; revisions received May 6, 1997; accepted for publication May 22, 1997.

Address for reprints: Chung-Ping Hsu, MD, Division of Thoracic Surgery, Department of Surgery, Taichung Veterans General Hospital, \#160, Sec 3, Taichung-Kang Rd., Taichung, Taiwan, Republic of China.

Copyright (C) 1997 by Mosby-Year Book, Inc.

$0022-5223 / 97 \$ 5.00+0 \quad \mathbf{1 2 / 1 / 8 3 4 1 0}$ surgical approaches have been applied to tumors of this particular anatomic site, focusing on either the thoracic side or the abdominal side. For a long period (before 1989), we performed tumor resections of the gastric cardia either through separate abdominal and thoracic incisions or through a thoracoabdominal incision with D1 to D2 lymph node dissection. However, experience showed that intrathoracic lymphatic spread up to the subcarinal level is unusual. ${ }^{6}$ Besides, with the use of the EEA stapling device (Auto Suture Company Division, United States Surgical Corporation, Norwalk, Conn.), a satisfactory segment of the distal esophagus can be resected and anastomosed safely. Since 1989, the majority of surgical resections for adenocarcinoma of the gastric cardia in this institute have been performed exclusively through the abdominal side. This retrospective cohort study presents our recent experience and results in treating adenocarcinoma of the gastric 
Table I. The clinical details of 70 cases of adenocarcinoma of the gastric cardia

\begin{tabular}{|c|c|c|}
\hline \multirow[b]{2}{*}{ Variables } & \multicolumn{2}{|c|}{ Patients } \\
\hline & No. & $\%$ \\
\hline \multicolumn{3}{|l|}{ Sex } \\
\hline Male & 52 & 74.3 \\
\hline Female & 18 & 25.7 \\
\hline \multicolumn{3}{|l|}{ Gastrectomy } \\
\hline Total & 63 & 90.0 \\
\hline Proximal & 7 & 10.0 \\
\hline \multicolumn{3}{|l|}{ Complication } \\
\hline Yes & 22 & 31.4 \\
\hline No & 48 & 68.6 \\
\hline \multicolumn{3}{|l|}{ Hospital mortality } \\
\hline Yes & 7 & 10.0 \\
\hline No & 63 & 90.0 \\
\hline \multicolumn{3}{|l|}{ Current status } \\
\hline Alive & 29 & 44.3 \\
\hline Dead & 41 & 55.7 \\
\hline \multicolumn{3}{|c|}{ Lymph node dissection } \\
\hline $\mathrm{D}$ & 5 & 7.1 \\
\hline D3 & 5 & 7.1 \\
\hline D4 & 60 & 85.8 \\
\hline \multicolumn{3}{|l|}{ Curability } \\
\hline$A$ & 12 & 17.1 \\
\hline $\mathrm{B}$ & 21 & 30.0 \\
\hline $\mathrm{C}$ & 37 & 52.9 \\
\hline \multicolumn{3}{|l|}{$\mathrm{T}$ stage } \\
\hline $\mathrm{TI}$ & 8 & 11.4 \\
\hline $\mathrm{T} 2$ & 7 & 10.0 \\
\hline $\mathrm{T} 3$ & 23 & 32.9 \\
\hline $\mathrm{T} 4$ & 32 & 45.7 \\
\hline \multicolumn{3}{|l|}{ N stage } \\
\hline No & 17 & 24.3 \\
\hline $\mathrm{N} 1$ & 18 & 25.7 \\
\hline $\mathrm{N} 2$ & 17 & 24.3 \\
\hline N3 & 1 & 1.4 \\
\hline N4 & 17 & 24.3 \\
\hline \multicolumn{3}{|l|}{ Stage } \\
\hline Ia & 6 & 8.6 \\
\hline $\mathrm{Ib}$ & 3 & 4.3 \\
\hline II & 8 & 11.4 \\
\hline IIIa & 13 & 18.6 \\
\hline IIIb & 17 & 24.3 \\
\hline IV & 23 & 32.9 \\
\hline
\end{tabular}

cardia by an abdominal approach with gastrectomy and radical lymphadenectomy (D2 to D4).

\section{Patients and methods}

Between January 1, 1989, and December 31, 1995, 392 patients with adenocarcinoma of the stomach, who underwent extended gastrectomy and radical lymphadenectomy (D2 to D4) at Taichung Veterans General Hospital, were included in this retrospective cohort study. The exclusion criteria for radical lymphadenectomy includes disseminated peritoneal tumor seeding, multiple organ invasion, and poor cardiopulmonary function of the patient. Among
Table II. Classification of nodal station for adenocarcinoma of the gastric cardia

\begin{tabular}{ccl} 
Group & Station & \multicolumn{1}{c}{ Name } \\
\hline N1 & 1 & Right cardiac \\
& 2 & Left cardiac \\
& 3 & Lesser curvature \\
& 4 & Greater curvature \\
N2 & 5 & Suprapyloric \\
& 6 & Infrapyloric \\
& 7 & Left gastric artery \\
& 8 & Common hepatic artery \\
& 9 & Celiac artery \\
& 10 & Splenic hilum \\
& 11 & Splenic artery \\
N3 & 12 & Hepatoduodenal ligament \\
& 13 & Retropancreatic \\
& 14 & Mesenteric root \\
N4 & 15 & Middle colic artery \\
& 16 & Paraaortic nodes \\
\hline
\end{tabular}

these, 70 consecutive patients with adenocarcinoma of the gastric cardia were enrolled in this study. The group comprised 52 men and 18 women. The mean ages at diagnosis for male and female patients were 65.8 years and 57.0 years, respectively. Table I shows the demographic data of these patients.

The majority of the operations were carried out exclusively through the abdominal side. Except for five proximal gastrectomies, a total gastrectomy was performed in all patients. The pancreas was preserved during lymph node dissection unless it was directly involved by the tumor. The alimentary continuity was restored by a Rouxen-Y esophagojejunostomy accomplished with a $25 \mathrm{~F}$ EEA stapler. The definition of nodal station (Table II) and curability of resection for carcinoma of the gastric cardia as set up by the Japanese Research Society for Gastric Cancer were adopted in this study. ${ }^{7}$ In brief, group 1 to 4 nodes, group 5 to 11 nodes, group 12 to 14 nodes, and group 15 and 16 nodes were classified as N1, N2, N3, and N4 groups, respectively. D2 stands for lymphadenectomy of the N1 and N2 groups; D3 stands for lymphadenectomy of the N1, N2, and N3 groups; and D4 stands for lymphadenectomy of the N1, N2, N3, and N4 groups. Patients with a T1 or T2 lesion, with the nodal metastasis confined to $\mathrm{N} 1$ group ( $\mathrm{N} 0$ or $\mathrm{N} 1$ ), with an adequate lymphadenectomy ( $\geq \mathrm{D} 1$ for $\mathrm{N} 0, \geq \mathrm{D} 2$ for $\mathrm{N} 1$ ), and without peritoneal seeding ( $\mathrm{P0}$ ), liver invasion $(\mathrm{HO})$, or distant metastasis (M0) who underwent gastric resection with a microscopically safe margin $(\geq 5 \mathrm{~mm}$ ) were classified as having curability A resection. Patients with peritoneal seeding, direct contagious organ invasion (T4) even after complete resection, or residual tumor were classified as having curability $\mathrm{C}$ resection. Patients in between were classified as having curability $B$ resection. No patient was lost to follow-up in the study period. All of the current survivors have been followed up for more than 12 months (12 to 81 months).

Survival probabilities were estimated by means of the Kaplan-Meier product-limit method. ${ }^{8}$ The log-rank test was used to interpret the statistical difference between 
Table III. Details of complications and causes of death

\begin{tabular}{lrr}
\hline & \multicolumn{2}{c}{ Episodes } \\
\cline { 2 - 3 } & No. & $\%$ \\
\hline Complications & 24 & 34.3 \\
Pancreatic fistula & 6 & 8.6 \\
Abdominal abscess & 6 & 8.6 \\
Anastomotic lcak & 3 & 4.3 \\
Respiratory failure & 2 & 2.9 \\
Wound infection & 2 & 2.9 \\
Upper GI bleeding & 1 & 1.4 \\
Lymphatic leak & 1 & 1.4 \\
Bile leak & 1 & 1.4 \\
Suffocation & 1 & 1.4 \\
Cerebral vascular accident & 1 & 1.4 \\
Deaths & 7 & 10.0 \\
Sepsis & 3 & 4.3 \\
Anastomotic leak & 1 & 1.4 \\
Pancreatic fistula & 1 & 1.4 \\
Abdominal abscess & 1 & 1.4 \\
Respiratory failure & 1 & 1.4 \\
Suffocation & 1 & 1.4 \\
Massive upper gastrointestinal bleeding & 1 & 1.4 \\
Cerebral vascular accident & 1 & 1.4 \\
\hline
\end{tabular}

${ }^{*}$ A total of 24 complications developed in 22 patients.

survival curves. The Cox proportional hazards model, ${ }^{8}$ assessed by the survival data of all 70 patients, was used for multivariable survival analysis in the manner of forward stepwise regression. The covariates were assigned to the model until the log-likelihood ratio stopped improving over the previous step at a 0.05 level. Then the prognostic factors were entered into the multivariable model, which offered a predictive relative hazards of mortality for the selected factors.

The association of an ordinal categoric response variable to a covariate was measured by the proportional odds model. ${ }^{9}$ The statistical significance of the relationship was assessed by likelihood ratio tests. The odds ratio of one unit increment in the covariate was derived from the model and evaluated the change of odds for patients likely to lie in higher levels of the ordinal response variable.

Survivals, Cox's model, and the proportional odds model were calculated by the $1 \mathrm{~L}, 2 \mathrm{~L}$, and PR programs, respectively, in the BMDP statistical software. ${ }^{10}$

\section{Results}

Current status of the patients. At the end point of this study (December 31, 1996), 29 patients were still alive and 41 patients had died. No patient was lost to follow-up. All of the patients had been followed up for at least 12 months (12 to 81 months).

Complications and deaths. There were 24 complications $(34.3 \%)$, which occurred in 22 patients
(31.4\%), and seven hospital deaths $(10.0 \%)$. The causes of complications and deaths are listed in Table III. The most common complications included pancreatic fistula and abdominal abscess, and the leading cause of death was sepsis.

Extent of radical lymph node dissection. Except in 10 patients with $\mathrm{T} 1$ or $\mathrm{T} 2$ tumors, all patients underwent lymph node dissection up to (and including) the N4 group. The types of lymphadenectomy included D2 in five patients, D3 in five, and D4 in 60 . The details concerning the number of lymph nodes that were removed and involved by the tumor are listed in Table IV. A total of 3121 (average 44.6 in 70 patients) lymph nodes were resected, and 691 (average 13.0 in 53 patients) lymph nodes had metastases. None of the D2 group had N2 group lymph node metastasis. One of the D3 group had N3 group lymph node metastasis. The relation between the extent of the lymphadenectomy and nodal metastasis is listed in Table V $(p=0.008)$. The odds ratio of $\mathrm{D} 4$ to $\mathrm{D} 2+\mathrm{D} 3$ was $5.9(95 \%$ confidence interval $[\mathrm{CI}]$ was 1.5 to 23.0). This showed that patients who underwent D4 dissection were 5.9 times more likely to have nodal metastases than patients having D2 + D3 dissection.

Depth of tumor invasion and its relation to lymph node metastasis. Early gastric cancer was found in eight patients $(11.4 \%$, mucosa in three and submucosa in five). Fifty-three (75.7\%) patients had lymph node metastasis. The rates of lymph node metastasis in T1 through T4 lesions were $25.0 \%, 71.4 \%, 82.6 \%$, and $84.4 \%$, respectively. The level of lymph node involvement was positively related to the depth of tumor invasion, as shown in Table V $(p=0.005)$. The odds ratios of $\mathrm{T} 3$ and $\mathrm{T} 4$ to $\mathrm{T} 1+\mathrm{T} 2$ were 4.7 (95\% CI was 1.4 to 17.0$)$ and $6.8(95 \% \mathrm{CI}$ was 2.0 to 23.0), respectively. The 5-year cumulative survivals of patients with T1 through T4 lesions were $100 \%$, $71.4 \%, 27.8 \%$, and $20.1 \%$, respectively. The 5-year cumulative survivals of patients with node-negative and node-positive disease were $68.4 \%$ and $27.5 \%$, respectively.

Curability of resection. Curability A resections were accomplished in 12 patients, curability $B$ resections in 21 patients, and curability $\mathrm{C}$ resections in 37 patients. The 5-year cumulative survivals of patients having curability $\mathrm{A}, \mathrm{B}$, and $\mathrm{C}$ resections were $100 \%$, $21.2 \%$, and $27.5 \%$, respectively. Curability A resections had a better prognosis than $\mathrm{B}$ and $\mathrm{C}$ resections (curability A vs curability B, $p=0.0003$; curability A vs curability $\mathrm{C}, p=0.00005$ ). 
Table IV. The details of lymphadenectomy according to 16 individual nodal stations

\begin{tabular}{lcr}
\hline \multicolumn{1}{c}{ Nodal station } & $\begin{array}{c}\text { Node dissected/patients } \\
\text { (mean) }\end{array}$ & $\begin{array}{c}\text { Node with metastasis/patients } \\
\text { (mean) }\end{array}$ \\
\hline 1. Right cardiac & $274 / 61(4.5)$ & $111 / 35(3.2)$ \\
2. Left cardiac & $148 / 43(3.4)$ & $37 / 20(1.9)$ \\
3. Lesser curvature & $406 / 65(6.2)$ & $154 / 41(3.8)$ \\
4. Greater curvature & $283 / 55(5.1)$ & $84 / 19(4.4)$ \\
5. Suprapyloric & $56 / 29(1.9)$ & $8 / 6(1.3)$ \\
6. Infrapyloric & $244 / 54(4.5)$ & $18 / 8(2.2)$ \\
7. Left gastric artery & $165 / 57(2.9)$ & $38 / 20(1.9)$ \\
8. Common hepatic artery & $283 / 62(4.6)$ & $45 / 17(2.6)$ \\
9. Celiac artery & $155 / 49(3.2)$ & $11 / 8(1.4)$ \\
10. Splenic hilum & $117 / 35(3.3)$ & $28 / 13(2.2)$ \\
11. Splenic artery & $206 / 53(3.9)$ & $61 / 19(3.2)$ \\
12. Hepatoduodenal ligament & $179 / 50(3.6)$ & $14 / 7(2.0)$ \\
13. Retropancreatic & $75 / 37(2.0)$ & $7 / 3(2.3)$ \\
14. Mesenteric root & $26 / 13(2.0)$ & $6 / 3(2.0)$ \\
15. Middle colic artery & $13 / 7(1.9)$ & $6 / 3(2.0)$ \\
16. Paraaortic nodes & $493 / 57(8.6)$ & $63 / 15(4.2)$ \\
Total & $3123 / 70(44.6)$ & $691 / 53(13.0)$ \\
\hline
\end{tabular}

Table V. Relationship of the nodal metastasis with extent of lymphadenectomy and depth of tumor invasion in proportional odds model

\begin{tabular}{|c|c|c|c|c|c|c|c|}
\hline \multirow[b]{2}{*}{ Factors } & \multicolumn{4}{|c|}{ Lymph node metastasis } & \multirow[b]{2}{*}{ Proportional odds ratio } & \multirow[b]{2}{*}{$95 \% \mathrm{CI}$} & \multirow[b]{2}{*}{$p$ Values } \\
\hline & NO & $N 1$ & $N 2$ & $N 3+4$ & & & \\
\hline Lymphadenectomy & & & & & & & 0.008 \\
\hline $\mathrm{D} 2+\mathrm{D} 3$ & 6 & 2 & 1 & 1 & 1 & & \\
\hline D4 & 11 & 16 & 16 & 17 & 5.9 & 1.5 to 23.0 & \\
\hline Depth of invasion & & & & & & & 0.005 \\
\hline $\mathrm{T} 1+\mathrm{T} 2$ & 8 & 4 & 2 & 1 & 1 & & \\
\hline $\mathrm{T} 3$ & 4 & 7 & 6 & 6 & 4.7 & 1.4 to 17.0 & \\
\hline $\mathrm{T} 4$ & 5 & 7 & 9 & 11 & 6.8 & 2.0 to 23.0 & \\
\hline
\end{tabular}

CI, Confidence interval.

TNM stage of the tumor. The clinicopathologic TNM stages of the patients were as follows: stage Ia, six patients; stage Ib, three patients; stage II, eight patients; stage IIIa, 13 patients; stage IIIb, 17 patients; and stage IV, 23 patients. The overall cumulative survival curve is shown in Fig. 1, with a 5-year survival of $37.6 \%$. The 5-year cumulative survivals in patients in pTNM stages I through IV were $100 \%, 62.5 \%, 23.0 \%$, and $17.4 \%$, respectively $(p=0.0004)$.

Prognostic factors. Multivariable survival analysis by Cox's proportional hazards model revealed that the level of nodal invasion $(p=0.02)$, the depth of tumor invasion $(p=0.01)$, and the presence of complications $(p=0.002)$ were independent prognostic factors. The relative hazards relating mortality to a prognostic factor with the adjustment of other factors are shown in Table VI.
Long-term follow-up and causes of death. At the end point of this study, 41 patients had died. Most of them died of systemic metastasis. No recurrences developed at the site of the esophageal anastomosis in our series, even though one patient had a diseased cut margin on pathologic examination. Another patient had severe gastroesophageal reflux after a proximal gastrectomy followed by esophagogastrostomy. A completion total gastrectomy was performed 21 months after the first operation, with recurrent tumor being found by chance at the gastric remnant. Nine months later, he underwent a third operation (transhiatal esophagectomy and colon interposition) because of tumor recurrence at the lower esophagus. This patient was still doing well 10 months after the third operation. None of the patients who underwent total gastrectomy followed by Roux-en-Y 


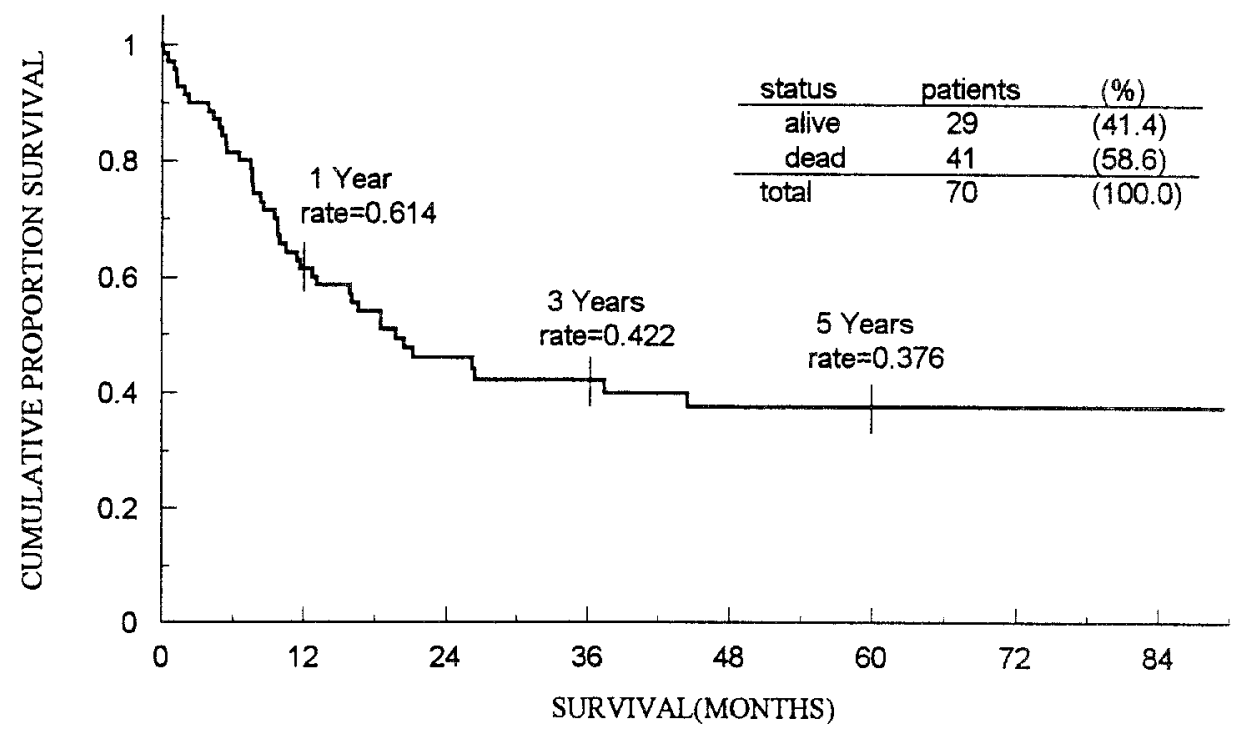

Fig. 1. Overall survivals in adenocarcinoma of the gastric cardia after radical lymphadenectomy.

esophagojejunostomy had symptomatic esophageal regurgitation.

\section{Discussion}

The incidence of carcinoma of the gastric cardia has increased steadily in recent years, especially in Western countries. ${ }^{5,11,12}$ Various definitions have been used to describe the "gastric cardia." "4, 13, 14 In this report, we use a broader definition based on the criteria proposed by the Japanese Research Society for Gastric Cancer. ${ }^{7}$ During the study period, 392 gastric carcinomas were managed by radical lymphadenectomy in this institute, and $70(17.9 \%)$ of them were adenocarcinoma of the gastric cardia. The prevalence of adenocarcinoma of the gastric cardia was roughly as reported by others. ${ }^{2,3}$

The generally accepted concept of severe gastroesophageal reflux after proximal gastrectomy has limited its clinical popularity in recent years. ${ }^{15}$ Besides, both inadequate surgical margins and limitations of lymphadenectomy are potential drawbacks. Five of our patients received a proximal gastrectomy; nevertheless, all of them had lymph node dissection up to the N4 group. Most of our patients (92.9\%) received a total gastrectomy and Roux-en- $Y$ type esophagojejunostomy to restore digestive tract continuity. All of the patients who underwent proximal gastrectomy $(n=5)$ had various degrees of gastroesophageal reflux. However, none of the patients who underwent total gastrectomy had symptoms of gastroesophageal reflux after a Roux-en-Y esophagojejunostomy or its modi- fications for bile diversion. It is still debatable whether to perform a combined resection of the spleen and pancreas. $^{1,16,17}$ Unless the pancreas is directly involved by the tumor, we prefer to perform a pancreaspreserving splenectomy during gastrectomy, as proposed by Maruyama and colleagues. ${ }^{18}$ Tumor metastases to the splenic hilum and splenic artery were observed in $13.6 \%$ and $25.4 \%$ of the patients, respectively. Six ( $8.6 \%$ ) pancreatic fistulas developed, one of which caused a hospital death. All of them occurred in patients who received a distal pancreatectomy. Our experience showed that a routine distal pancreatectomy is not necessary for lymph node dissection at the splenic hilum, pancreatic tail, and along the course of the splenic artery. Adequate lymphadenectomy can be obtained, and pancreatic fistula can be avoided.

Great concern about the length of distal esophagectomy has been raised and emphasized..$^{3,19-21}$ However, others have preferred an abdominal approach for resection of carcinoma of the gastric cardia. ${ }^{1,2,22}$ We believe that the type of operation is basically dependent on the type of tumor and its extent of esophageal involvement. ${ }^{23}$ In Western countries, more type I cancers of the cardia (originating from Barrett's epithelium) were encountered, although most of our cardia cancers were either type II or type III instead. We had only one proved case of Barrett's esophagus inducing early adenocarcinoma of the cardia in this series. Since 1989 , the majority of gastrectomies for adenocarcinoma of the gastric cardia have been performed 
exclusively through an abdominal approach. We found that resection of the distal esophagus through an enlarged hiatus is not difficult. Usually the esophagus can be transected at least 3 to $6 \mathrm{~cm}$ above the tumor border. The digestive continuity then can be restored by an EEA stapler instead of by hand sewing. With this approach, respiratory complications can be minimized, and the likelihood of anastomotic leakage can be lowered when compared with results of previous experience $(4.3 \%$ vs $7.6 \%$, $p=0.4) .{ }^{24}$ Residual tumor on the esophageal cut margin or anastomotic recurrence was not a major problem in our series. Only one of our patients had a microscopically diseased esophageal cut end on pathologic examination. Postoperative irradiation was implemented, and local recurrence did not develop before he died of liver metastasis. Furthermore, none of the patients had tumor recurrence at the residual esophageal segment. We believe longdistance submucosal tumor infiltration in adenocarcinoma of the gastric cardia is not so frequently seen as it is in squamous cell carcinoma of the esophagus. A safe margin of 3 to $6 \mathrm{~cm}$ above the tumor is mandatory. Another reason for adopting a transabdominal approach emanates from a report from one of our associated hospitals, which demonstrated zero incidence of lymph node metastasis at the subcarinal region. ${ }^{6}$ We therefore recommend a transabdominal approach for resection of adenocarcinoma of the gastric cardia.

The importance of radical lymphadenectomy has been repeatedly emphasized, especially in the Japanese series. ${ }^{1,2,25}$ Its benefits had even been pointed out in node-negative early gastric carcinoma and in noncurative gastrectomy. ${ }^{26,27}$ The adequacy of lymphadenectomy in this series can be proved by an average of 44.6 dissected nodes per patient. D2 dissection was performed in five patients (T1 in three, $\mathrm{T} 2$ in two), and none of them had N2 metastasis. D3 dissection was performed in five patients ( $\mathrm{T} 1$ in four, $\mathrm{T} 3$ in one), and only one patient had N3 metastasis. The remainder $(n=60,85.7 \%)$ received radical lymphadenectomy to the paraaortic region. Complications related to lymphadenectomy were pancreatic fistula, abdominal abscess, and prolonged lymphatic leak. The overall complication and mortality rates of $31.4 \%$ and $10.0 \%$ were higher than in our previous experience $(17.4 \%, p=0.009 ; 5.9 \%, p=$ $0.3)$, but they were similar to the Dutch experiences. $^{28}$

Our data furthermore demonstrated that the level
Table VI. Multivariable survival analysis by Cox's proportional hazards model $(n=70)$

\begin{tabular}{llll}
\hline \multicolumn{1}{c}{ Variables } & Hazard ratio & $95 \%$ CI & $p$ Values \\
\hline Lymph node metastasis & & & 0.02 \\
N0 & 1 & & \\
N1 & 0.89 & 0.28 to 2.81 & \\
N2 & 2.13 & 0.73 to 6.24 & \\
N3 + N4 & 3.45 & 1.18 to 10.04 & \\
Depth of invasion & & & 0.01 \\
T1 + T2 & 1 & & \\
T3 & 7.78 & 1.70 to 35.68 & \\
T4 & 9.69 & 2.10 to 44.70 & \\
Complication & & & \\
No & 1 & & \\
Yes & 2.81 & 1.45 to 5.45 & 0.002 \\
\hline
\end{tabular}

$\mathrm{Cl}$, Confidence interval.

of nodal metastasis is closely related to the depth of tumor invasion ( $p=0.005$ ), as reported by others. $^{29,30}$ Moreover, multivariable analysis revealed that both the $\mathrm{T}$ factor and $\mathrm{N}$ factor are independent prognostic factors, as they were in the German report. ${ }^{31}$ The prognoses of patients with $\mathrm{T} 3$ to $\mathrm{T} 4$ tumors or patients with N3 to N4 nodal metastasis are much worse than the prognoses of their counterparts.

Not only the stage of the tumor, but also the degree of curability in resection is important for prognostic prediction. A curability A resection provides the best opportunity for long-term survival. According to the definition of the Japanese Research Society for Gastric Cancer, only patients with a $\mathrm{T} 1$ or $\mathrm{T} 2$ lesion, with their nodal metastasis confined to $\mathrm{N} 1$ group ( $\mathrm{N} 0$ or $\mathrm{N} 1$ ), with an adequate lymphadenectomy ( $\geq \mathrm{D} 1$ for $\mathrm{N} 0, \geq \mathrm{D} 2$ for $\mathrm{N} 1$ ), and without peritoneal seeding ( $\mathrm{P} 0)$, liver invasion $(\mathrm{H} 0)$, or distant metastasis (M0), and who underwent gastric resection with a microscopically safe margin ( $\geq 5 \mathrm{~mm}$ ) can be classified as having had a curability A resection. Unlike the Japanese reports, the diagnosis in most of our patients was made at a relatively late stage. Only $12(17.1 \%)$ procedures can be classified as curability A resections. On the contrary, more than half $(n=37,52.9 \%)$ of our patients received a curability $\mathrm{C}$ resection. The main reason for the stage of disease being classified as advanced was detection of $\mathrm{T} 4$ lesion or direct invasion of the regional omentum or mesocolon by the tumor during the operation. Both of these factors subsequently led to an overall poorer outcome. Early diagnosis provides the only way to achieve a curability A resection and long-term survival.

Early gastric cancers (mucosa and submucosa) 
were identified in eight patients; however, only six of them had node-negative disease (stage Ia). This group of patients, together with those having T2 N0 and T1 N1 (stage Ib, $n=3$ ) disease, all had a $100 \%$ survival at 5 years. Once the tumor invaded beyond the submucosal layer (T3 and T4 lesions), 82.3\% (51 of 62 patients) of the patients in this series had nodal involvement. Except in T1 tumor, our data support a radical lymphadenectomy to achieve complete tumor resection. Besides, accurate tumor staging can be obtained only through a thorough lymphadenectomy. This is also essential for elimination of the stage migration phenomenon. ${ }^{32}-$ An overall 5year survival of $37.6 \%$ was obtained in this series, which was much better than a previous report from this institute $\left(6.7 \%\right.$ 5-year survival). ${ }^{24}$ To some extent, we believe that the changes in our attitude toward adenocarcinoma of the gastric cardia, using a more radical intraabdominal lymphadenectomy in addition to extended gastrectomy, contributed to the better outcome in this series. Comparison of the survivals revealed statistically significant survival differences among different stages $(p=0.0004)$. Patients with stage I and stage II tumors had 5-year survivals of $100.0 \%$ and $62.5 \%$, respectively. A tumor of stage IIIa or above indicates a poor prognosis, but the results in this study are still better than our previous results.

Long-term follow-up of the patients revealed that the majority died of systemic metastasis. Local recurrence at the esophageal anastomotic site was not observed if an adequate length (more than $3 \mathrm{~cm}$ ) was excised. However, a local recurrence did develop at the gastric remnant after a proximal gastrectomy in one patient. Despite a completion total gastrectomy, a local recurrence still developed at the lower end of the esophagus, which led to a transhiatal esophagectomy and colon interposition, as described in the Results section. Thus a proximal gastrectomy should be avoided whenever possible, not only to eliminate gastroesophageal reflux, but also to prevent tumor recurrence at the gastric remnant.

Our experience demonstrates that through an abdominal approach (extended gastrectomy including distal esophagectomy), radical lymphadenectomy can be safely performed with an acceptable morbidity and mortality rate. Esophagojejunostomy with an EEA stapler through an enlarged esophageal hiatus significantly decreased the prevalence of anastomotic leak. However, increased intraabdominal complications associated with radical lymphad- enectomy were observed. Long-term survival of these patients was dramatically improved in this institute by a more aggressive attitude with the use of extended gastrectomy and radical lymphadenectomy for adenocarcinoma of the gastric cardia.

\section{REFERENCES}

1. Noguchi $Y$, Imada T, Matsumoto A, Coit DG, Brennan MFF. Radical surgery for gastric cancer: a review of the Japanese experience. Cancer 1989;64:2053-62.

2. Maruyama K, Gunven P, Okabayashi K, Sasako M, Kinoshita T. Lymph node metastases of gastric cancer: general pattern in 1931 patients. Ann Surg 1989;210:596-602.

3. Moreaux J, Msika S. Carcinoma of the gastric cardia: surgical management and long-term survival. World J Surg 1988;12: 229-35.

4. Allum WH, Roginski C, Fielding JWL, et al. Adenocarcinoma of the cardia: a 10 -year regional review. World J Surg 1986;10:462-7.

5. Pera M, Cameron AJ, Trastek VF, Carpenter HA, Zinsmeister AR. Increasing incidence of adenocarcinoma of the esophagus and esophagogastric junction. Gastroenterology 1993;104:510-3.

6. Wang LS, Wu CW, Hsieh MJ, Fahn HJ, Huang MH, Chien KY. Lymph node metastasis in patients with adenocarcinoma of gastric cardia. Cancer 1993;71:1948-53.

7. Japanese Research Society for Gastric Cancer. Japanese classification of gastric carcinoma. 1st English ed. Tokyo: Kanehara \& Co; 1995; p. 15,39-65.

8. Armitage P, Berry G. Statistical methods in medical research. 3rd ed. Oxford: Blackwell Science; 1994.

9. McCullagh, P, Nelder JA. Generalized linear models. 2nd ed. Chapman Hall, London; 1989.

10. Dixon WJ. BMDP statistical software. Los Angeles: University of California Press; 1987.

11. Bolt WJ, Defssa SS, Kneller RW, Fraumeni JF. Rising incidence of adenocarcinoma of the esophagus and gastric cardia. JAMA 1991;265:1287-9.

12. Craanen ME, Dekker W, Blok, P, Ferwerda J, Tytgat GNJ. Time trends in gastric carcinoma: changing patterns of types and location. Am J Gastroenterol 1992;87:572-9.

13. Misumi A, Murakami A, Harada K, Baba K, Akagi M. Definition of carcinoma of the gastric cardia. Langenbecks Arch Chir 1989;374:221-6.

14. Skinner DB. Gastroesophageal junction. In: Skinner DB, Belsey RHR, Hendrix TR, Zuidema GD, editors. Anatomy, chap 2. Gastroesophageal reflux and hiatal hernia. Boston: Little Brown; 1972. p. 12-6.

15. Siewert JR, Böttcher K, Stein HJ, Roder JD, Busch R. Problem of proximal third gastric carcinoma. World J Surg 1995; 19:523-31.

16. Brady MS, Rogatko A, Dent LL, Shiu MH. Effect of splenectomy on morbidity and survival following curative gastrectomy for carcinoma. Arch Surg 1991;126:359-64.

17. Okajima K, Izozaki H. Splenectomy for treatment of gastric cancer: Japanese experience. World J Surg 1995;19:537-40.

18. Maruyama K, Sasako M, Kinoshita T, Sano T, Katai H, Okajima K. Pancreas-preserving total gastrectomy for proximal gastric cancer. World J Surg 1995;19:532-6.

19. Paolini A, Tosato F, Cassese M, et al. Total gastrectony in 
the treatment of adenocarcinoma of the cardia: review of the results in 73 resected patients. Am J Surg 1986;151:238-43.

20. Papachristou DN, Agnanti N, D'Agostino H, Fortner JG. Histologically positive esophageal margin in the surgical treatment of gastric cancer. Am J Surg 1980;139:711-3.

21. Akiyama $\mathrm{H}$, Miyazono $\mathrm{H}$, Tsurumaru $\mathrm{M}$, Hashimoto $\mathrm{C}$, Kawamura T. Thoracoabdominal approach for carcinoma of the cardia of the stomach. Am J Surg 1979;137:345-9.

22. Misumi A, Misumi K, Harada K, Murakami A, Kondo H, Akagi M. Transabdominal operation for carcinoma of the gastric cardia: application of pulling-up retractor and EEA stapler. Int Surg 1989;74:223-8.

23. Siewert JR, Stein HJ. Carcinoma of the cardia: carcinoma of the gastroesophageal junction--classification, pathology and extent of resection. Dis Esoph 1996;9:173-82.

24. Wang PY, Chien KY. Surgical treatment of carcinoma of the esophagus and cardia among the Chinese. Ann Thorac Surg 1983;35:143-51.

25. Jatzko GR, Lisborg PH, Denk H, Klimpfinger M, Stettner HM. A 10-year experience with Japanese type radical lymph node dissection for gastric cancer outside Japan. Cancer 1995;76:1302-12.
26. Baba H, Maehara $Y$, Takeuchi $H$, et al. Effect of lymph node dissection on the prognosis in patients with node-negative early gastric cancer. Surgery 1995;117:165-9.

27. Baba $\mathrm{H}$, Maehara $\mathrm{Y}$, Inutsuka $\mathrm{S}$, et al. Effectiveness of extended lymphadenectomy in noncurative gastrectomy. Am J Surg 1995;169:261-4.

28. Bonenkamp JJ, Songun I, Hermans J, et al. Randomized comparison of morbidity after D1 and D2 dissection for gastric cancer in 996 Dutch patients. Lancet 1995;345: $745-8$.

29. Soga J, Kobayashi K, Saito J, Fujimaki M, Muto T. The role of lymphadenectomy in curative surgery for gastric cancer. World J Surg 1979;3:701-8.

30. Wang $\mathrm{HH}$, Antonioli DA, Goldman $\mathrm{H}$. Comparative features of esophageal and gastric adenocarcinomas: recent changes in type and frequency. Hum Pathol 1986;17:482-7.

31. Hermanek P. Prognostic factors in stomach cancer surgery. Eur J Surg Oncol 1986;12:241-6.

32. Feinstein AR, Sosin DM, Wells CK. The Will Rogers phenomenon: stage migration and new diagnostic techniques as a source of misleading statistics for survival in cancer. N Engl J Med 1985;312:1604-8.

\section{Availability of Journal back issues}

As a service to our subscribers, copies of back issues of The Journal of Thoracic and Cardiovascular Surgery for the preceding 5 years are maintained and are available for purchase from Mosby at a cost of $\$ 15.00$ per issue until inventory is depleted. The following quantity discounts are available: $25 \%$ off on quantities of 12 to 23 , and one third off on quantities of 24 or more. Please write to Mosby-Year Book, Inc., Subscription Services, 11830 Westline Industrial Drive, St. Louis MO 63146-3318, or call 800-453-4351 or 314-453-4351 for information on availability of particular issues. If unavailable from the publisher, photocopies of complete issues may be purchased from UMI, 300 N. Zeeb Rd., Ann Arbor, MI 48106, 313-761-4700. 